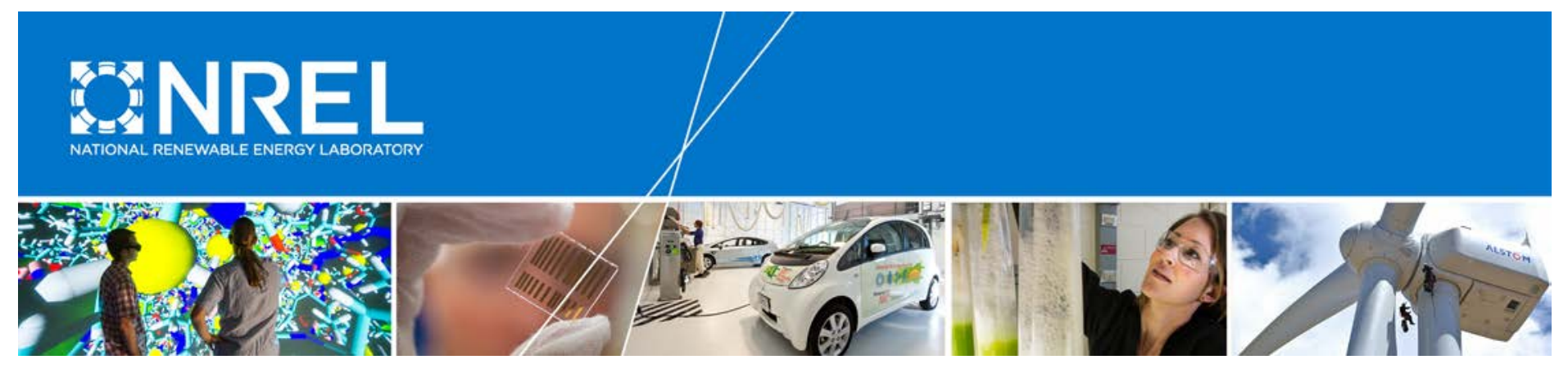

\title{
Evaluation and Field Assessment of Bifacial Photovoltaic Module Power Rating Methodologies
}

\section{Preprint}

Chris Deline, Sara MacAlpine, and Bill Marion National Renewable Energy Laboratory

Fatima Toor and Amir Asgharzadeh University of lowa

Joshua S. Stein Sandia National Laboratories

Presented at the 43rd IEEE Photovoltaic Specialists Conference Portland, Oregon June 5-10, 2016

(c) 2016 IEEE. Personal use of this material is permitted. Permission from IEEE must be obtained for all other uses, in any current or future media, including reprinting/republishing this material for advertising or promotional purposes, creating new collective works, for resale or redistribution to servers or lists, or reuse of any copyrighted component of this work in other works.

NREL is a national laboratory of the U.S. Department of Energy Office of Energy Efficiency \& Renewable Energy Operated by the Alliance for Sustainable Energy, LLC

This report is available at no cost from the National Renewable Energy Laboratory (NREL) at www.nrel.gov/publications.

Conference Paper

NREL/CP-5J00-66496

June 2016

Contract No. DE-AC36-08G028308 


\section{NOTICE}

The submitted manuscript has been offered by an employee of the Alliance for Sustainable Energy, LLC (Alliance), a contractor of the US Government under Contract No. DE-AC36-08GO28308. Accordingly, the US Government and Alliance retain a nonexclusive royalty-free license to publish or reproduce the published form of this contribution, or allow others to do so, for US Government purposes.

This report was prepared as an account of work sponsored by an agency of the United States government. Neither the United States government nor any agency thereof, nor any of their employees, makes any warranty, express or implied, or assumes any legal liability or responsibility for the accuracy, completeness, or usefulness of any information, apparatus, product, or process disclosed, or represents that its use would not infringe privately owned rights. Reference herein to any specific commercial product, process, or service by trade name, trademark, manufacturer, or otherwise does not necessarily constitute or imply its endorsement, recommendation, or favoring by the United States government or any agency thereof. The views and opinions of authors expressed herein do not necessarily state or reflect those of the United States government or any agency thereof.

This report is available at no cost from the National Renewable Energy Laboratory (NREL) at www.nrel.gov/publications.

Available electronically at SciTech Connect http:/www.osti.gov/scitech

Available for a processing fee to U.S. Department of Energy and its contractors, in paper, from:

U.S. Department of Energy

Office of Scientific and Technical Information

P.O. Box 62

Oak Ridge, TN 37831-0062

OSTI http://www.osti.gov

Phone: 865.576.8401

Fax: 865.576.5728

Email: reports@osti.gov

Available for sale to the public, in paper, from:

U.S. Department of Commerce

National Technical Information Service

5301 Shawnee Road

Alexandria, VA 22312

NTIS http://www.ntis.gov

Phone: 800.553 .6847 or 703.605 .6000

Fax: 703.605.6900

Email: orders@ntis.gov 


\title{
Evaluation and Field Assessment of Bifacial Photovoltaic Module Power Rating Methodologies
}

\author{
Chris Deline, ${ }^{1}$ Sara MacAlpine, ${ }^{1}$ Bill Marion, ${ }^{1}$ Fatima Toor, ${ }^{2}$ Amir Asgharzadeh, ${ }^{2}$ and Joshua S. Stein ${ }^{3}$ \\ ${ }^{1}$ National Renewable Energy Laboratory, Golden, CO, 80401, USA \\ ${ }^{2}$ University of Iowa, Iowa City, IA, 52242, USA \\ ${ }^{3}$ Sandia National Laboratories, Albuquerque, NM, 87123, USA
}

\begin{abstract}
- 1-sun power ratings for bifacial modules are currently undefined. This is partly because there is no standard definition of rear irradiance given $1000 \mathrm{Wm}^{-2}$ on the front. Using field measurements and simulations, we evaluate multiple deployment scenarios for bifacial modules and provide details on the amount of irradiance that could be expected. A simplified case that represents a single module deployed under conditions consistent with existing 1-sun irradiance standards leads to a bifacial reference condition of $1000 \mathrm{Wm}^{-2} G_{\text {front }}$ and 130-140 $\mathrm{Wm}^{-2} G_{\text {rear }}$. For fielded systems of bifacial modules, $G_{\text {rear }}$ magnitude and spatial uniformity will be affected by self-shade from adjacent modules, varied ground cover, and groundclearance height.

A standard measurement procedure for bifacial modules is also currently undefined. A proposed international standard is under development, which provides the motivation for this work. Here, we compare outdoor field measurements of bifacial modules with irradiance on both sides with proposed indoor test methods where irradiance is only applied to one side at a time. The indoor method has multiple advantages, including controlled and repeatable irradiance and thermal environment, along with allowing the use of conventional single-sided flash test equipment. The comparison results are promising, showing that the indoor and outdoor methods agree within $1 \%-2 \%$ for multiple rear-irradiance conditions and bifacial module types.
\end{abstract}

\section{INTRODUCTION}

Existing photovoltaic (PV) module measurements are governed by the multiple parts of IEC 60904 [1], which discuss indoor and outdoor measurement of PV modules. In particular, this standard describes the reference irradiance resource that constitutes a 1-sun Standard Test Condition (STC) power measurement. These reference conditions and translations are currently defined only for a monofacial resource; rearside irradiance conditions and bifacial measurement methods are presently undefined in the IEC standards. A new proposal [2] intends to provide specificity for power measurement and rating of bifacial PV modules. The proposal is for indoor power rating of bifacial modules; here, we compare this indoor measurement proposal with comparable outdoor power measurements.

Bifacial cells and modules have been discussed in the past [3] and are characterized by their ability to collect light on both the front and rear of the cell. The energy generated by bifacial PV modules over similar monofacial designs depends greatly on the deployment scenario and environmental conditions, but additional energy gain of 5\%-25\% has been demonstrated [4] under a variety of ground-cover scenarios and mounting configurations. However, on the topic of standard 1-sun power measurement, the literature is less clear, with only a few prior discussions $[5,6,7,8]$. In particular, it would be advantageous to identify the rearside irradiance resource that occurs under the conditions assumed by IEC 60904-3. These conditions are explicitly defined as Air Mass (AM) 1.5 spectrum, $1000 \mathrm{Wm}^{-2}$ irradiance, over a light baresoil ground cover [9].

In this paper, we present a simulation of front and rear irradiance under two scenarios supported by field data. We then use the validated irradiance model to predict rear irradiance for a single module deployed under the aforementioned monofacial reference conditions, and conduct sensitivity studies on the impact of deployment height and the amount of light transmitted through the module. We finally compare the proposed indoor single-sided measurement method with outdoor power measurements on two different bifacial module types. We demonstrate that the proposed indoor methodology is consistent with outdoor measurements for the particular modules that we tested.

\section{IRRADIANCE SIMULATION AND MODEL VALIDATION}

Bifacial simulations are set up with the open-source software RADIANCE [10]. This simulation tool provides physically realistic image rendering and illuminance mapping, and it has been used previously for the modeling of bifacial PV installations [11]. Model illumination approximates the Perez direct and diffuse model [12], and calculates reflections from surfaces of defined albedo and surface roughness.
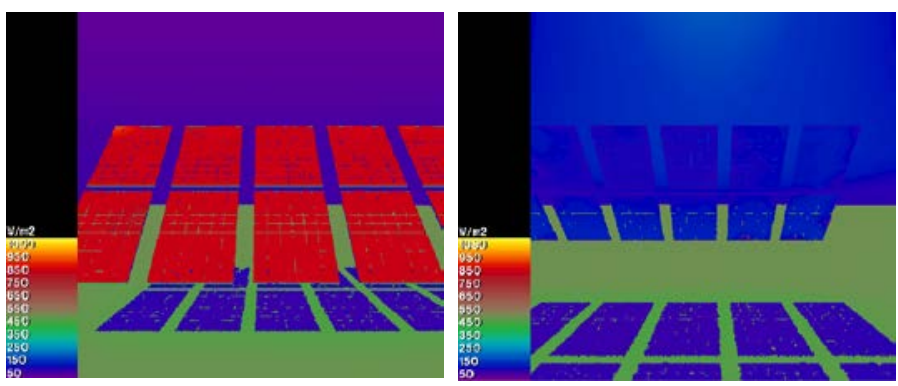

Fig. 1: RADIANCE simulation of Array 1 for a sunny noontime condition. $G_{\text {front }}$ is $844 \mathrm{Wm}^{-2}$ and $G_{\text {rear }}$ is $80-90 \mathrm{Wm}^{-2}$. 
Scenarios have been created approximating two experimental arrays in order to validate the accuracy of the RADIANCE simulation methodology. Rather than focus on multiple irradiance conditions, a single sunny noontime irradiance condition is chosen for model validation (Fig. 1).

Additional scenarios were constructed to specifically look at proposed bifacial reference conditions. These sensitivity studies focus on the deployment scenario of a single module deployed over 0.21 albedo ground cover, with $1000 \mathrm{Wm}^{-2}$ front irradiance at $37^{\circ}$ tilt angle. The first sensitivity study looks at the impact of ground-clearance height $z$ whereas the second investigates the effect of different cell spacing within the bifacial PV module, because irradiance transmitted through the module can increase the available backside resource.

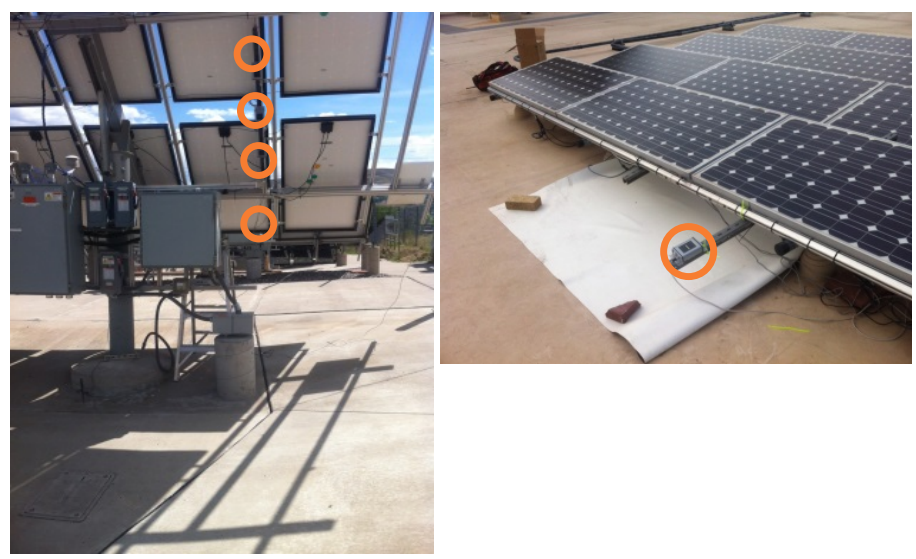

Fig. 2: Array 1 (left) is mounted $1 \mathrm{~m}$ above concrete at $40^{\circ}$ tilt. Array 2 (right) is a close-mount rooftop system at $10^{\circ}$ tilt above either beige or white roofing material. Front-facing irradiance is measured along with rearside irradiance at 3-4 positions (circles).

\section{A. Model validation arrays}

Front and rear irradiance are measured over a period of time for two different PV installations (Fig. 2). Calibrated, crystalline silicon PV reference cells (IMT Solar Si-01TC) are used to take the irradiance measurements with data collected on a remote data logger every minute.

Array 1 is a pedestal-mount PV system at $40^{\circ}$ tilt, which matches deployment conditions consistent with IEC 60904-3. The ground beneath the array is light concrete, measured to have a slightly higher average reflectance $(R=0.28)$ than that of the reference standard $(R=0.21)$. There are some objects behind the array (inverter housing) that affect the uniformity of rearside irradiance.

Array 2 is a rooftop system at $10^{\circ}$ tilt mounted about 30 $\mathrm{cm}$ above the surface. This is a deployment scenario that might be considered for bifacial PV modules, although the particular modules used in this installation are monofacial. Ground cover is beige built-up-roof material, with reflectance $R$ measured between 0.25 and 0.43 due to soiling. A white EPDM material $(R=0.8)$ was deployed under the array during some measurements to test the benefit of a more reflective surface.

\section{IRRADIANCE MEASUREMENT AND SIMULATION RESULTS}

\section{A. Model validation results}

Measured and modeled results for Array 1 are shown in Fig. 3 as a ratio of rearside-to-frontside irradiance at noon on a sunny day. (Results are similar at other times of the day.) In this array, measured and modeled rear-irradiance fraction $\left(G_{\text {rear }} / G_{\text {front }}\right)$ falls between 0.1 and 0.14 with a slight height dependence. For $\mathrm{Z}=1.5 \mathrm{~m}$, measured $G_{\text {rear }}$ is slightly low. This discrepancy is likely due to obstructions behind the array in the field of view of the lowest sensor, because the $Z=1 \mathrm{~m}$ measurement is again in good agreement with simulation.

These measurements are similar to prior results that have also shown relatively uniform irradiance above a height of $1 \mathrm{~m}$, and rear-irradiance ratios between 0.1 and 0.15 , given ground cover of this albedo $[4,6]$.

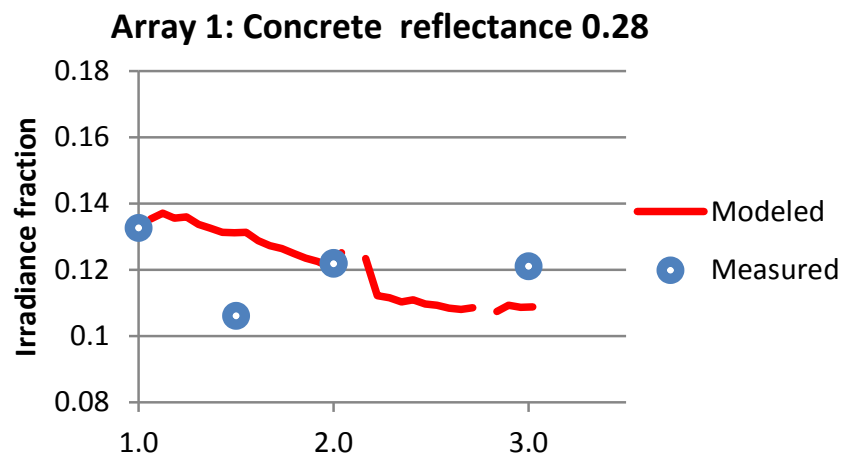

$\mathrm{Z}$ height above ground $(\mathrm{m})$

Fig. 3: Measured (circle) and modeled (line) $G_{\text {rear }} / G_{\text {front }}$ for Array 1

The second model validation case Array 2 has four long rows of modules. We have investigated front and rear irradiance along a chord from south to north along all four of the module rows. Figure 4 shows both measured and modeled $G_{\text {rear }} / G_{\text {front }}$. In this plot, $\mathrm{X}=0$ indicates the southernmost (front) edge of each row.

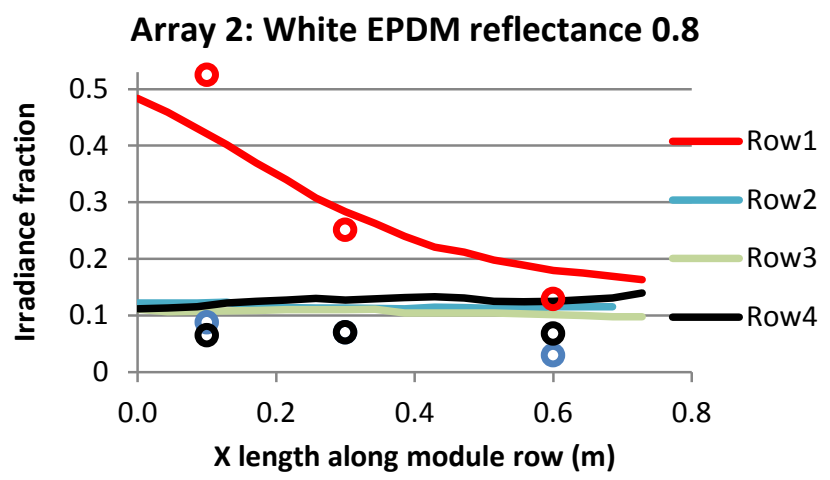

Fig 4: Measured (circle) and modeled $G_{\text {rear }} / G_{\text {front }}$ irradiance fraction for each of four rows in Array 2. 
In this case, the measured and modeled results are in relatively good agreement. In particular, the first row has much higher $G_{\text {rear }}$ than interior rows, and there is a strong irradiance gradient from the front of the module to the back in the first row. For interior rows, while modeled predictions are for $G_{\text {rear }} / G_{\text {front }}$ around $0.1-0.12$, measured values are lower (0.04-0.07). This may be due to angle-of-incidence losses in the reference cells that are not reflected in the model, as well as other model inaccuracies.

Figures 3 and 4 indicate that the magnitude and uniformity of $G_{\text {rear }}$ depend greatly on the geometry of PV system deployment, as well as ground-cover reflectance.

\section{$B$. Reference condition sensitivity analysis}

A reference deployment scenario for specification of standard rear irradiance is now described, consistent with [1] and illustrated in Fig. 5-namely, a single module deployed over light soil (0.21 albedo) ground cover, with $1000 \mathrm{Wm}^{-2}$ front irradiance at $37^{\circ}$ tilt angle. One factor that is not specified by existing standards is the ground clearance $z$ of the bifacial module during measurement. This parameter is adjusted in simulations, with average rear irradiance $G_{\text {rear }}$ and irradiance nonuniformity shown in Fig. 6. The latter term is defined as:

$$
\text { Nonuniformity }=\left[\frac{\max G_{r e a r}-\min G_{\text {rear }}}{\max G_{\text {rear }}+\min G_{\text {rear }}}\right] .
$$

Spatial uniformity reaches $5 \%$ or Class ' $\mathrm{B}$ ' standard around a 1-m deployment height, which also coincides with $G_{\text {rear }} \approx$ $130 \mathrm{Wm}^{-2}$.
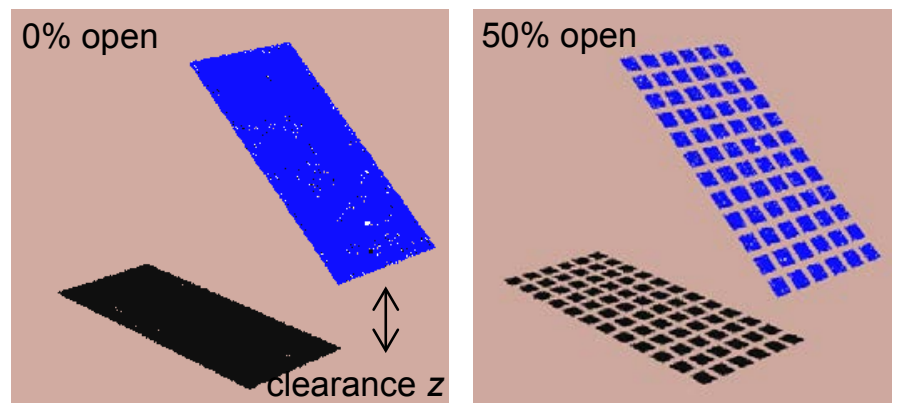

Fig. 5: Single module deployment scenario representative of the IEC 60904-3 irradiance standard, namely $1000 \mathrm{Wm}^{-2}$ front irradiance, $37^{\circ}$ tilt angle and light soil ground cover. Two sensitivity studies are conducted here: ground clearance $\mathrm{z}$ and fraction of module transparent area.

A second sensitivity study looks at the effect of open area within a PV module. Under field-deployment conditions, one would expect an increase in rear irradiance as cell spacing increases and more light is transmitted through the module. However, this is undesirable from a standardization standpoint because ideally there should be a single rearirradiance test value for any module construction type. Fortunately, as Fig. 7 indicates, with sufficient ground clearance (e.g. $z>1 \mathrm{~m}$ ), $G_{\text {rear }}$ is impacted only slightly by module transparent area.

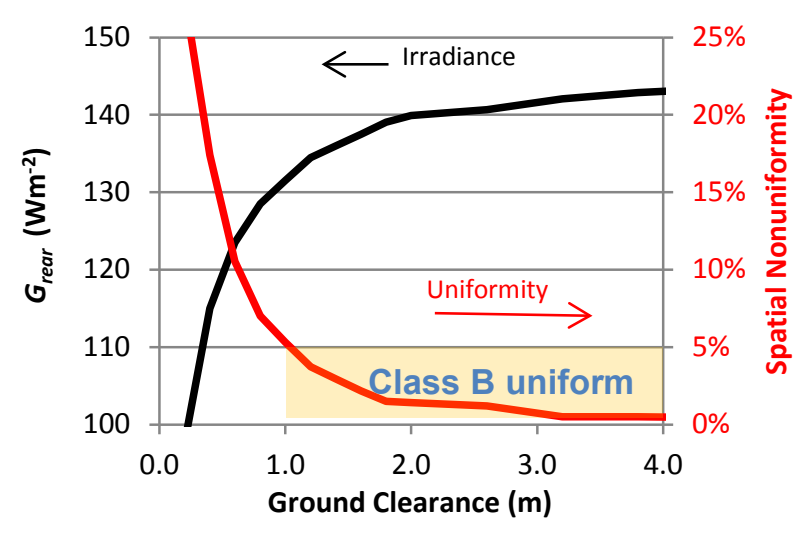

Fig. 6: Simulated average rear irradiance on a module deployed at $37^{\circ}$ tilt angle over light soil ( 0.21 albedo) given various groundclearance values $z$. Nonuniformity across the module (right axis) is reduced as $z$ increases.

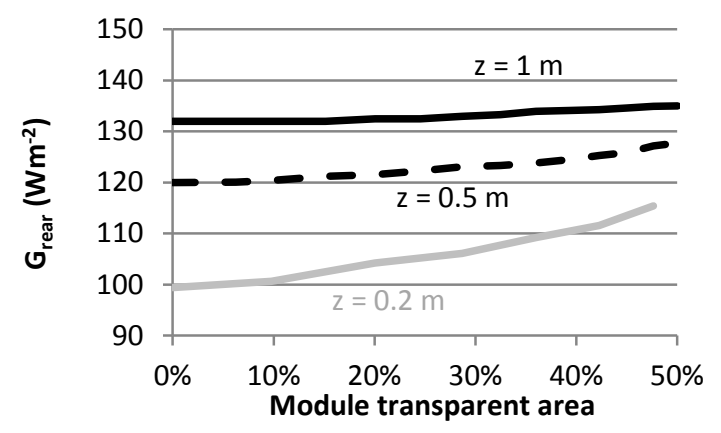

Fig. 7: Modeled rear irradiance as a function of the fraction of the light that is transmitted through the module using the conditions from Fig. 5. Transparent space between cells has an impact on $G_{\text {rear }}$ at low ground clearance.

The result of the sensitivity simulations indicate that for a single module deployment consistent with the monofacial reference standard, the average value and uniformity of $G_{\text {rear }}$ depends on the ground clearance $z$. At sufficient height $z=$ $1 \mathrm{~m}$, the spatial uniformity reaches Class ' $\mathrm{B}$ ' or $5 \%$ uniformity, and the impact of the module transparent area on $G_{\text {rear }}$ is also minimized. The value of $G_{\text {rear }}$ under these conditions is $130-140 \mathrm{Wm}^{-2}$, depending on deployment height and sun angle. Note that although this value may be representative of a single module deployed under representative STC conditions, real field deployments will experience a range of $G_{\text {rear }}$ values, as shown in Figs. 3 and 4.

\section{INDOOR AND OUTDOOR STC MODULE MEASUREMENTS}

Bifacial modules were measured indoors and outdoors at STC, i.e., 1-sun front irradiance and $25^{\circ} \mathrm{C}$ module temperature. Multiple rear-irradiance conditions were considered because a standard rear-irradiance value has yet to be agreed upon. The intent here is to establish a positive agreement between indoor one-sided flash simulator methods and outdoor measurements for bifacial modules. Indoor 
measurements were taken at $25^{\circ} \mathrm{C}$ using a Spire 5600 or FMT350 flash simulator. When measured indoors, the unilluminated side of the bifacial module is covered to limit unintended light exposure.

Outdoor measurements were taken on an open-frame rack with adjustable tilt and orientation, shown in Fig. 8. Four reference cells (one front, three back) provide information on the front and rear irradiance $G_{\text {front }}$ and $G_{\text {rear }}$. The reference cells have a good spectral and incidence-angle match to the module under test, reducing errors from nearby obstructions and ground-cover changes. A $G_{\text {front }}$ target close to $1000 \mathrm{Wm}^{-2}$ was achieved by tilt and azimuth adjustment of the rack. $G_{\text {rear }}$ is measured at three locations to ensure rear-irradiance uniformity. Through fine tuning of the nearby ground cover (as seen in Fig. 8), rear-irradiance nonuniformity of $<5 \%$ was achieved for all measurements according to Eq. (1).

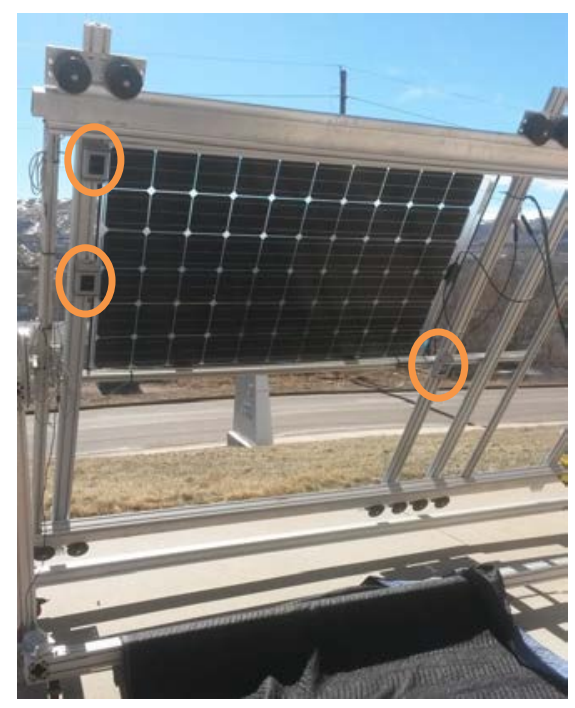

Fig. 8: Outdoor bifacial module measurement configuration, showing three rear-facing reference cells (circled) and dark ground cover to reduce the $G_{\text {rear }}$ gradient.

During winter conditions, outdoor module temperatures of $25^{\circ} \mathrm{C}$ were achieved, as measured by back-of-module thermocouples. Warmer ambient conditions required temperature correction to $25^{\circ} \mathrm{C}$ using known $\beta_{P m p}$ coefficients.

Module current-voltage (IV) curves were collected under several $G_{\text {rear }}$ conditions using a custom electronic load. The magnitude of $G_{\text {rear }}$ varies naturally with the time of day and orientation of the rack. High values of $G_{\text {rear }}$ were achieved by deploying a high-reflectance $(R=0.8)$ white EPDM material behind the rack, still maintaining irradiance spatial nonuniformity $<5 \%$. Conversely, low values of $G_{\text {rear }} \approx 0$ were achieved by covering the back of the module with a black opaque blanket during measurement.

\section{A. Indoor bifacial equivalent irradiance $G_{E}$}

The equivalence of indoor one-sided test methods with outdoor measurements rests on the assumption that the shortcircuit current $\left(I_{s c}\right)$ of the module varies linearly with front and rear irradiance, and that the $I_{s c}$ under bifacial illumination is equal to the sum of the current generated from both sides of the module, i.e., once the carriers have been generated, it makes no difference to the module from which side the light entered the module. This fact has been affirmed previously $[8,13]$ and will be further validated here.

The "bifaciality" of a solar cell is sometimes defined as the ratio of rear efficiency to front efficiency. However, these parameters depend on the irradiance at which efficiency is measured, and they are further affected by module construction type and junction-box position. As an alternative, we define here $B i F i_{I s c}$ to be the ratio

$$
B i F i_{\text {Isc }}=I_{s c 0, \text { rear }} / I_{s c 0, \text { front }}
$$

where $I_{s c 0, \text { rear }}$ and $I_{s c 0 \text {,front }}$ are single-sided STC short-circuit current of the rear and front of the module, respectively. We now define indoor bifacial irradiance equivalent $G_{E}$, namely, the single-sided indoor flash irradiance that replicates 1-sun $G_{f}$ and simultaneous $G_{\text {rear }}$ rear irradiance:

$$
G_{E}=1000 \mathrm{Wm}^{-2}+B i F i_{I S C} \cdot G_{\text {rear }}
$$

$G_{E}$ is an elevated irradiance accounting for both 1-sun front illumination plus the additional $G_{\text {rear }}$ illumination, moderated by the reduced ability of the rear of the bifacial cell to generate photocarriers. Equation (3) allows indoor singlesided flash measurements to be compared directly with field test measurements of bifacial modules deployed under various $G_{\text {rear }}$ conditions.

\section{B. Bifacial measurement results and discussion}

Two modules were measured using the indoor and outdoor test platforms. Module $\mathrm{A}$ is a glass-glass module with measured $B i F i_{I s c}=0.91$. For the outdoor deployment, six $G_{\text {rear }}$ conditions between 0 and $131 \mathrm{Wm}^{-2}$ were achieved. This translates to indoor $G_{E}$ values between $1000 \mathrm{Wm}^{-2}$ and 1119 $\mathrm{Wm}^{-2}$. Indoor measurements were taken on a Spire 5600 flash simulator.

Module B is a framed construction module with low rearcell efficiency: $B i F i_{I s c}=0.39$. The outdoor deployment achieved five $G_{\text {rear }}$ conditions between 0 and $292 \mathrm{Wm}^{-2}$ (with the help of $R=0.8$ white roofing material). Because of the lower $B i F i_{I s c}$ for Module $\mathrm{B}$, a $G_{E}$ range similar to that for Module $\mathrm{A}$ is required-between $1000 \mathrm{Wm}^{-2}$ and $1114 \mathrm{Wm}^{-2}$. Indoor measurements are taken on two separate flash simulators: Spire 5600 and FMT-350.

Measurement uncertainty in this experiment is estimated at $2 \%$ due to differences in irradiance sensors, electronic load accuracy, and irradiance spectrum between the various measurement platforms. Temperature and irradiance corrections also contribute to measurement uncertainty. 


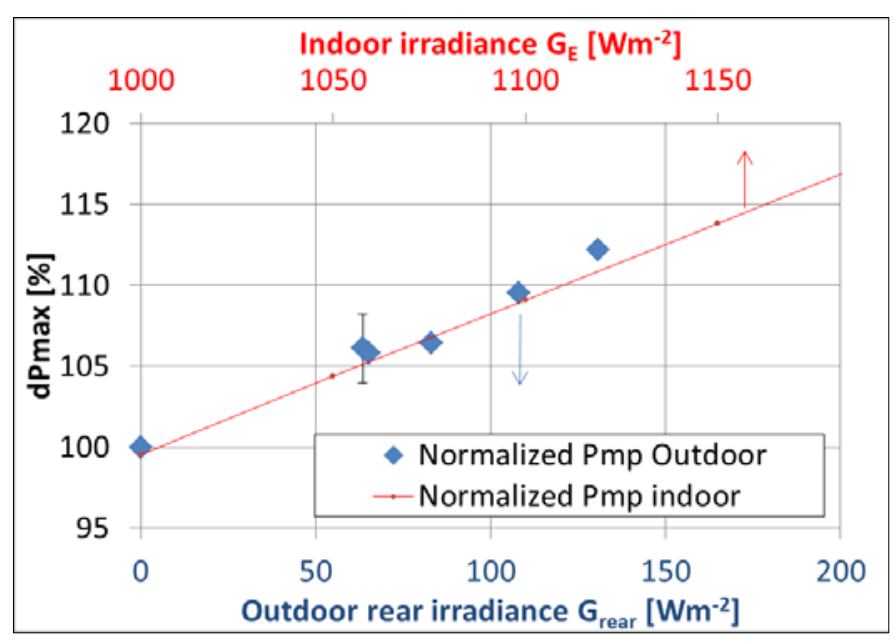

Fig. 9: Module A indoor and outdoor module power normalized by front-only $P_{m p 0}$. Module A $B i F i_{I s c}=0.91$

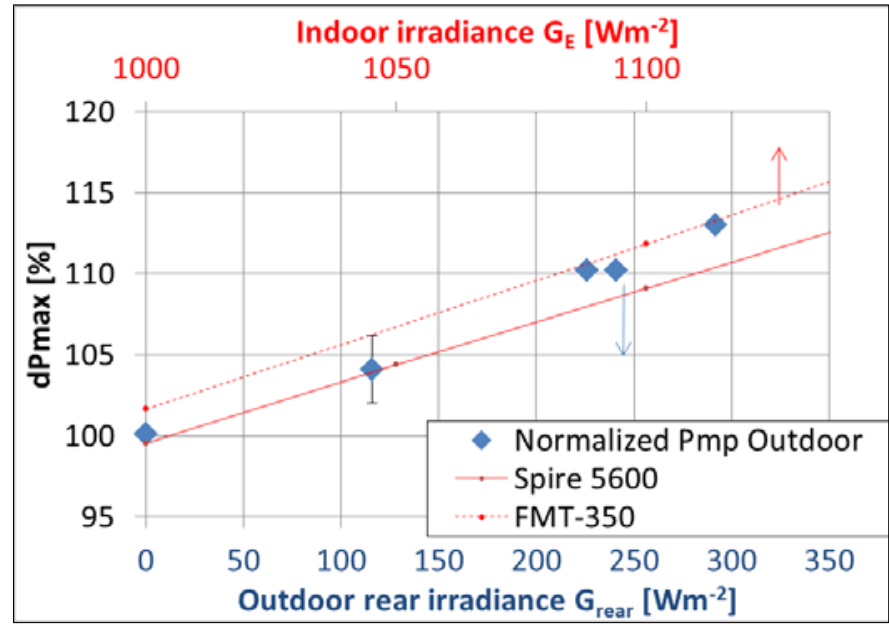

Fig. 10: Module B indoor and outdoor power normalized by frontonly $P_{m p 0}$. Module B $B i F i_{I s c}=0.39$. Two indoor flash simulators are used (Spire 5600 and FMT-350) showing 2\% relative difference mainly in $I_{s c}$.

Results are shown in Figs. 9 and 10 for Modules A and B, respectively. For these plots, measured power values are normalized by front-only STC power: dPmax $=P_{m p} / P_{m p 0}$. Good agreement exists between outdoor simultaneous illumination and indoor one-sided measurement, within $1 \%$ for module A and within our 2\% margin of error for Module $\mathrm{B}$. In the case of Module B, where two indoor simulator platforms were used, the outdoor measurements are bounded by the results of these two platforms, which displayed a consistent $2 \%$ difference. The difference in indoor platforms was due mainly to discrepancy in measured $I_{s c}$, which is often attributed to differences in irradiance reference device, as well as differences in spatial uniformity or spectral mismatch of the test platforms.
It is interesting that a wide range of $G_{\text {rear }}$ values were achieved by the outdoor test platform. Measurements over concrete ground cover $(\mathrm{R}=0.28)$ varied from $G_{\text {rear }}=62 \mathrm{Wm}^{-}$ ${ }^{2}$ to $G_{\text {rear }}=131 \mathrm{Wm}^{-2}$ depending on tilt angle and the visible extent of ground cover to the rear of the module. Substitution of a high $R=0.8$ ground cover increased the measured $G_{\text {rear }}$ range from $226 \mathrm{Wm}^{-2}$ to $292 \mathrm{Wm}^{-2}$. This highlights the fact that while we may be able to identify a rear-irradiance magnitude and uniformity for use in a 1-sun standard, real-life deployments of bifacial modules can expect to see a variety of $G_{\text {rear }}$ conditions.

\section{CONCLUSIONS}

A ray-tracing simulation model was described and benchmarked against measurements from several PV field deployments. Conditions consistent with the IEC 60904-3 monofacial irradiance standard were recreated, and the rear irradiance simulated for a proposed bifacial reference condition, namely a single module deployed at $1-\mathrm{m}$ height over 0.21 albedo (light soil) ground cover with $1000 \mathrm{Wm}^{-2}$ front irradiance. Sensitivity analysis shows that for modules with a range of transparent area between cells and a height of at least $1 \mathrm{~m}$ above the ground, this configuration results in $G_{\text {rear }}=130-140 \mathrm{Wm}^{-2}$. For fielded bifacial systems, a range of $G_{\text {rear }}$ values will be more realistic, depending on groundsurface albedo and rack spacing.

Comparison of outdoor bifacial field measurements with a proposed one-sided indoor test method yielded positive results. Two bifacial module types were considered, representing a range of construction types and efficiency characteristics. In both cases, indoor and outdoor methods agreed within $1 \%-2 \%$, indicating that the proposed singlesided indoor test methodology can faithfully characterize bifacial modules with the use of conventional laboratory and production-line measurement equipment.

\section{ACKNOWLEDGMENTS}

Special thanks to Steve Rummel (NREL) and Harrison Wilterdink (Sinton Instruments) for module measurements.

This work was supported by the U.S. Department of Energy under Contract No. DE-AC36-08GO28308 with the National Renewable Energy Laboratory.

\section{REFERENCES}

[1] IEC 60904-3, Photovoltaic Devices - Part 3: Measurement Principles for Terrestrial Photovoltaic (PV) Solar Devices with Reference Spectral Irradiance Data, 2008.

[2] V. Fakhfouri, "Photovoltaic Devices - Part 1-2: Measurement of Current-Voltage Characteristics of Bifacial Photovoltaic (PV) Devices," Proposal 82/1044/NP, July 28, 2015.

[3] A. Cuevas, The Early History of Bifacial Solar Cells Proceedings of the $20^{\text {th }}$ European Photovoltaic Solar Energy Conference,. 2005. 
[4] U.A. Yusufoglu, T.M. Pletzer, L.J. Koduvelikulathu, C. Comparotto, R. Kopecek, and H. Kurz, "Analysis of the Annual Performance of Bifacial Modules and Optimization Methods," IEEE Journal Of Photovoltaics 5 pp. 320-328, 2015

[5] D. Faiman, D. Berman, D. Bukobza, S. Kabalo, I. Karki, B. Medwed, V. Melnichak, E. de Held, and H. Oldenkamp, "A Field Method for Determining the Efficiency of Each Face of a Bi-Facial Photovoltaic Module", $3^{\text {rd }}$ World Conference on Photovoltaic Energy Conversion May 11-18, 2003.

[6] C. Duran, P. Hering, T. Buck, and K. Peter, "Characterization of Bifacial Silicon Solar Cells and Modules: A New Step", European Photovoltaic Solar Energy Conference, 2011.

[7] L. Kreinin, N. Bordin, A. Karsenty, A. Drori, D. Grobgeld, and Y. Eisenberg, "PV Module Power Gain due to Bifacial Design.. Preliminary Experimental and Simulation Data , $35^{\text {th }}$ IEEE PVSC, 2010, pp. 002171-002175. [8] J. Singh, A. Aberle, and T. Walsh, "Electrical Characterization Method for Bifacial Photovoltaic Modules," Solar Energy Materials \& Solar Cells 127 pp. 136-142, 2014.

[9] C. A. Gueymard, C. Myers, and K. Emery, "Proposed Reference Irradiance Spectra for Solar Energy Systems Testing," Solar Energy 73 pp. 443-467, 2002.

[10] G. J. Ward, "The RADIANCE Lighting Simulation and Rendering System," Proceedings of the $21^{\text {st }}$ Annual Conference on Computer Graphics and Interactive Techniques, ACM, 1994. Software available at https://github.com/NREL/Radiance/releases

[11] C. Lo, Y. Lim, and F. Rahman, "New Integrated Simulation Tool for the Optimum Design of Bifacial Solar Panel with Reflectors on a Specific Site," Renewable Energy 81 pp. 293307, 2015.

[12] R. Perez, R. Seals, and J. Michalsky, "All-Weather Model for Sky Luminance Distribution-Preliminary Configuration and Validation," Solar Energy 50 pp. 235-245, 1993.

[13] H. Ohtsuka, M. Sakamoto, M. Koyama, K. Tsutsui, T. Uematsu, and Y. Yazawa, "Characteristics of Bifacial Solar Cells under Bifacial Illumination with Various Intensity Levels," Progress in PV 9, pp. 1-13, 2001. 